\title{
Gravity Drainage Process For Miscible and Immiscible Co2 Injection Process
}

\author{
Ahammad Sharif Mohammed ${ }^{1}$, Dr. C.V.Subramanyam ${ }^{2}$ \\ \{ahmedsharif.chem95@gmail.com¹,cvsrvr@gmail.com² \\ Research Scholar, Acharya Nagarjuna University, Guntur 522001, India \& \\ Assistant Professor, GIET college of Engineering, Rajahmundry, 533294, India ${ }^{1}$, \\ Professor, RVR\&JC College of Engineering, Guntur 522001, India ${ }^{2}$
}

\begin{abstract}
In this paper, $\mathrm{CO} 2$ injection for enhancing oil recovery assisted by gravity drainage using reservoir simulation (using CMG's IMEX and GEM simulators) for a miscible and immiscible process is studied. The reservoir pressure declines with time and reaches a point where the fluids from the reservoir will not flow into the wellbore. Then the reservoir is assisted by additional pressure support under secondary recovery methods by gas injection or water flooding. For the conditions where the reservoir is having immobile oil due to relation of fluid and rock properties enhanced oil recovery techniques are adopted. $\mathrm{CO} 2$ is used under gas injection techniques is one of the most efficient and economic method to recover the oil. The gravity drainage process of $\mathrm{CO} 2$ when injected into the reservoir is observed in this paper. To understand and analyze the process of gravity drainage under miscible and immiscible $\mathrm{CO} 2$ injection a $50^{\circ} \mathrm{API}$ gravity oil was selected to study under simulation model of selected grid size. The analysis was made for seven different cases and their relations with time, production of water and GOR are represented.
\end{abstract}

Keywords: $\mathrm{CO}_{2}$ injection, gravity drainage, gas injection, miscible and immiscible flow, API gravity, reservoir simulation.

\section{Introduction}

Enhanced oil recovery is to recover the immobile oil when the reservoir pressure declines and flow of oil ceases. There are various EOR techniques used to recover the left-over oil. Gas injection technique is the most efficient economic method of enhancing the recovery rates. The gas injection is carried out as a miscible displacement or immiscible displacement based on the reservoir. The miscibility of an injected gas directly depends on the MMP(Minimum Miscibility Pressure). The $\mathrm{CO}_{2}$ injection being the one of most efficient enhanced oil recoveries, the field studies indicate that there are no investigations on the gravity drainage process for immiscible \& miscible $\mathrm{CO}_{2}$ injection. There is also a lack of research on the gravity drainage process for $50^{\circ} \mathrm{API}$ gravity oils. An attempt was made to study the $\mathrm{CO}_{2}-$ assisted gravity drainage to understand the mode of miscibility development, gas injection, molecular diffusion and heterogeneity through grid refinement studies. Thus, a study is carried out by using Computer Modeling Group (CMG), IMEX and GEM simulator by selecting compositional models based on equation of state and pseudo-miscible. To avoid premature breakthroughs and viscous fingering through oil zones the injection rates are maintained below the critical levels. 
To study $\mathrm{CO}_{2}$ - assisted gravity drainage enhanced oil recovery method's, miscibility development and recovery performance on $50^{\circ} \mathrm{API}$ gravity oils compositional models a set of seven combinations of $\mathrm{CO}_{2}$ injection rates and production rates of oil. This process considers maintaining the process at void balance conditions. In this study, the data is considered from optimized oil recovery of vertical injection of $\mathrm{CO}_{2}$ and horizontal oil production from a regular well. A period of 132 years set for reservoir simulation for miscible and immiscible $\mathrm{CO}_{2}$ injection.

Table 1. Rate Constraints of The Wells

\begin{tabular}{|c|c|c|c|}
\hline \multirow[t]{3}{*}{ CASE } & \multicolumn{3}{|c|}{ Rate Constraints/Well } \\
\hline & \multicolumn{2}{|c|}{$\mathrm{iCO}_{2} \mathrm{MMSCFD}$} & \multirow[t]{2}{*}{$\mathrm{Q}_{\mathrm{o}}, \mathrm{BPD}$} \\
\hline & Immiscible & Miscible & \\
\hline I & $1.50 \mathrm{E}+06$ & $2.09 \mathrm{E}+06$ & 4000 \\
\hline II & $3.32 \mathrm{E}+06$ & $4.70 \mathrm{E}+06$ & 9000 \\
\hline III & $5.62 \mathrm{E}+06$ & $7.80 \mathrm{E}+06$ & 15000 \\
\hline IV & $1.00 \mathrm{E}+07$ & $1.40 \mathrm{E}+07$ & 20000 \\
\hline $\mathrm{V}$ & $2.00 \mathrm{E}+07$ & $2.74 \mathrm{E}+07$ & 52500 \\
\hline VI & $3.00 \mathrm{E}+07$ & $4.10 \mathrm{E}+07$ & 80000 \\
\hline VII & $4.00 \mathrm{E}+07$ & $5.60 \mathrm{E}+07$ & 108000 \\
\hline
\end{tabular}

\section{Comparing}

- INCREMENTAL OIL RECOVERY

The production of oil that was left for secondary recovery is incremental oil recovery.

Incremental EOR $=$ Incremental Oil Recovered in $\mathrm{CO}_{2}-$ Assisted Gravity Drainage Oil-In-Place at the start of $\mathrm{CO}_{2}$ injection

The immiscible and miscible rate constraints of the incremental oil recovery performance of $\mathrm{CO}_{2}$ injected with respective pore volumes are represented by figures $1 \& 2$.

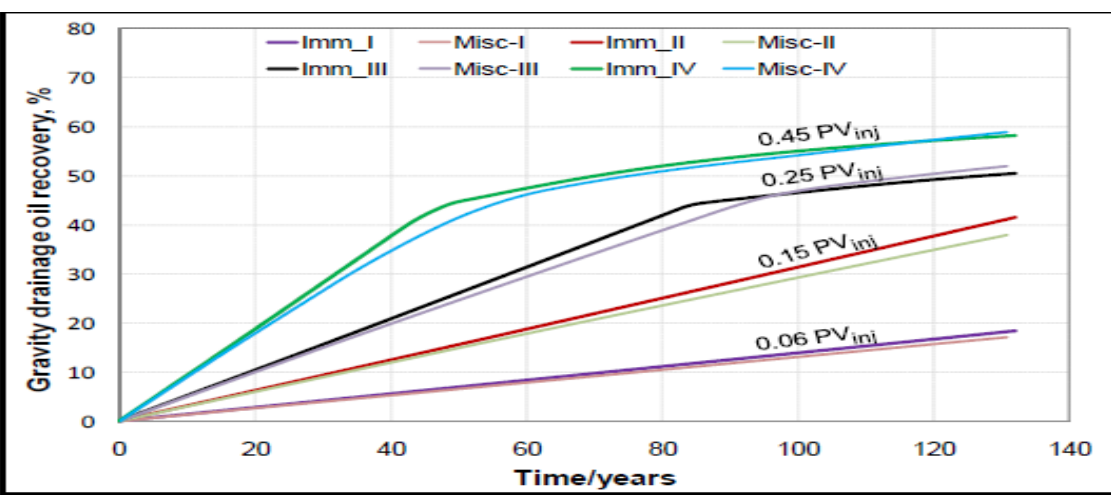

Fig. 1: Comparison between incremental miscible and immiscible gravity drainage assisted by $\mathrm{CO}_{2}$ oil recovery in rate-constraints from Case-I to Case-IV 
From the figure 1 graph, it is clear that the recovery rates are less for miscible compared to immiscible for a case I \& II low rate constraints. But for cases III \& IV there is a marginal cross for miscible over immiscible recovery. For Case $-\mathrm{V}$ the incremental recovery showed relatively higher for miscible compared to the immiscible process. The same was seen for Case-IV but there was an early flood front 30 years before.

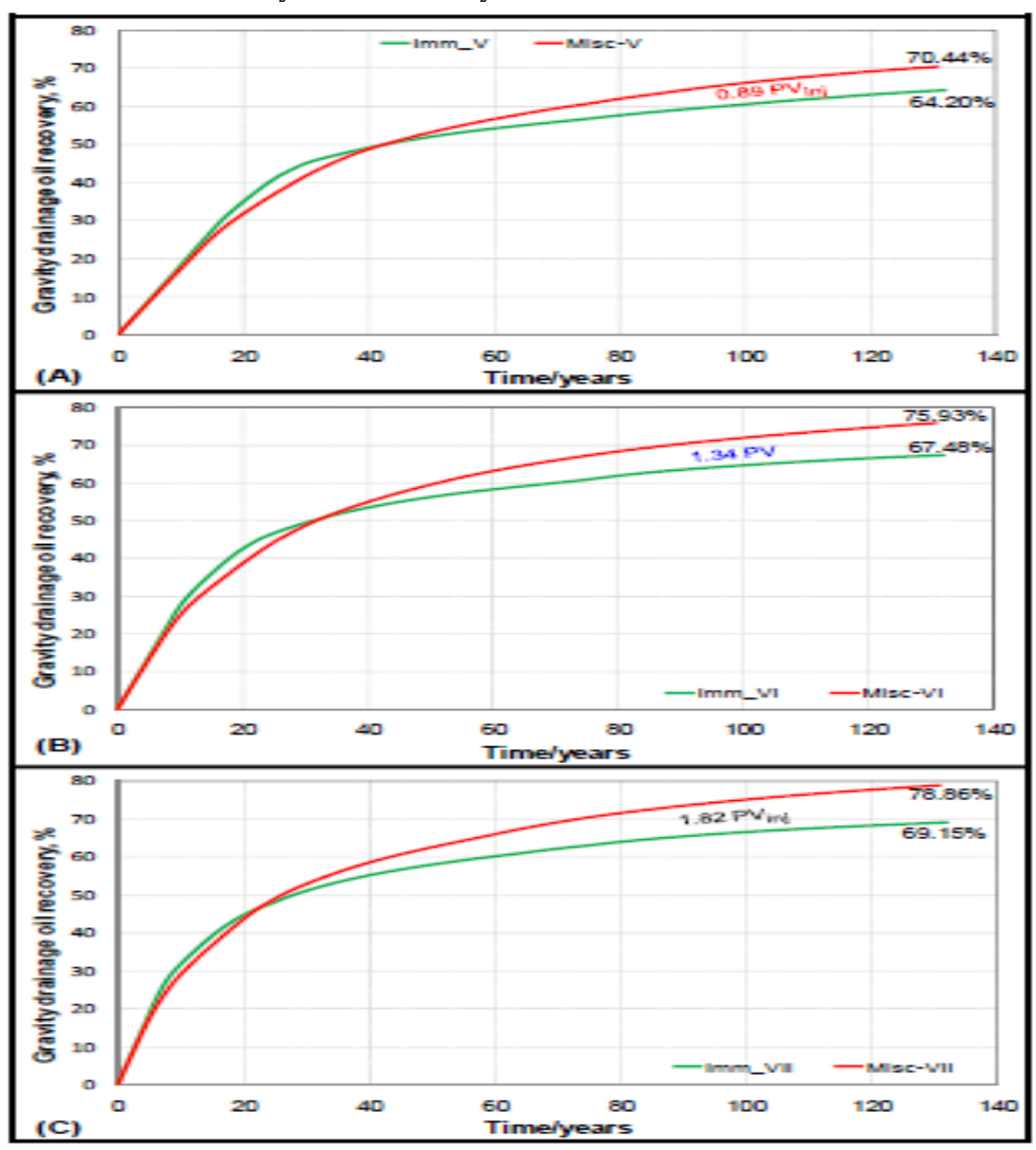

Fig. 2: Comparison - Incremental $\mathrm{CO}_{2}$-assisted gravity drainage oil recoveries in both the immiscible and miscible process from Case-V to Case-VII

For Case - VII there was the highest incremental recovery from the higher $\mathrm{CO}_{2}$ injection rates that accounted a $79 \%$. This is $10 \%$ more than the immiscible flood for the same conditions in Case-VI.

From a detailed understanding of the above curves, it is clear that the immiscible recovery projected higher levels than miscible till the $\mathrm{CO}_{2}$ flood front is achieved.

- GOR: 
The GOR (Gas Oil Ratio) of Case IV - Case VII for the taken rate constraints showed a thinning curve for the miscible process and thick curves for the immiscible process. For CaseVII immiscible process had a maximum of 96000 GOR and 85875 for the miscible process. GOR in miscible tends to stay low due to the injected high-pressure gas compress the condensate gas. But as the selected oil is of $50{ }^{\circ} \mathrm{API}$ gravity which is a light oil that may produce condensate gas. This will show gas production after a breakthrough.

\section{- WATER PRODUCTION:}

For Case IV-VII the water production from the water breakthrough by the aquifer below the oil zone for miscible and immiscible is zero or negligible. This is as the horizontal reservoirs are perorated and produced at parallels. The vertical injection of $\mathrm{CO}_{2}$, the proper selection of producing zone and correct selection of control or completely nullify the chances of water coning.

\section{- RESERVOIR PRESSURE:}

As the reservoir pressure declines with time as production happens, the study of the average pressure decline for the life of the reservoir is critical and highly needed. From the set of data combinations, there was a decrease of 60 psia till the drainage area achieved $\mathrm{CO}_{2}$ flood front in the horizontal production well which is a 2.2 psi/year decline by 2022 . The drop in oil production and the rise in GOR indicate the $\mathrm{CO}_{2}$ flood front arrival. The average pressure for Case -IV, VI \& VII after production for 132 years under immiscible process is observed a decline of 22,70 and 100 psi respectively. The wells with high-rate constraints have more pressure drops than low rate well constraints. For the three cases of IV, VI \& VII the pressure drops are as 0.17 psi, 0.54 psi, and 0.77 psi per year correspondingly which explains that the wells with low-rate constraints have less pressure drop.

\section{Study Of Mechanism}

\section{- IMMISCIBLE}

For immiscible $\mathrm{CO} 2$ gas injection assisted by gravity drainage EOR method block $(21,20,7)$ is selected to evaluate the contributing mechanisms are demonstrated by figure 3 are changes that are associated with properties over 132 years of production which is done by understanding the oil saturation profile by combining with pressure in reservoir and GOR. The oil saturation in case-V and VII for 16 and 7 years respectively in a block $(21,20,7)$ remains constant at 0.82 .

\section{- MISCIBLE}

From earlier comparative studies it is shown that the incremental recovery of the miscible flood was high than the immiscible process. The responsible mechanisms that aided high recovery are illustrated by understanding oil saturation, gas saturation, and oil viscosity properties.

To sum up, the average reservoir pressure is the dominating mechanism that contributed to oil recovery by EOR process of gravity drainage assisted by $\mathrm{CO}_{2}$ under miscible and immiscible process. This is well understood by collaborating oil rate Barrel Per Day (BPD), 
GOR (ratio of gas oil ) and average pressure in reservoir for the miscible and immiscible process are discussed in detail.

\subsection{OVERALL MECHANISMS: IMMISCIBLE AND MISCIBLE PROCESS}

In EOR process for both the miscible and immiscible gravity drainage assisted by $\mathrm{CO}_{2}$, the average pressure in reservoir is the parameter which itself explains the involved mechanism of oil recovery. Figure 3 shows the oil rate per barrel per day, GOR (ratio of gas oil) and the average pressure in reservoir in both miscible and immiscible process in Case- $\mathrm{V}$ were plotted in order to understand.

At initial stage of immiscible flood of $\mathrm{CO}_{2}$ the average pressure in reservoir is 2633 psia in March 1995 but at end (April 2126), it is nearly 2598 psia (see in Figure 3A). This was dropped by only 35 psia, with 026 psia rate of average every year in 132 years of simultaneous production and immiscible $\mathrm{CO}_{2}$ injection. The production of oil begins just after the injection of $\mathrm{CO}_{2}$ (see in figure $3 \mathrm{~A}$ ). In the secondary flood of $\mathrm{CO}_{2}$ it was observed that the single phase oil flow and the water phase was immobile. The difference in the higher density between gas and oil at the time of secondary immiscible flood and that promotes the under gravity oil drainage behind the flood front of $\mathrm{CO}_{2}$. This type of drained oil joins with oil bank formed earlier the flood front of $\mathrm{CO}_{2}$ for further contribution of oil-displacement which takes place before the flood front of $\mathrm{CO}_{2}$.

The majority of oil was in oil bearing zone in oil bank. In respect with the sharp drop in saturation of gas the saturation of oil in block $(25,14,6)$ is slowly increased in 8 years of miscible process from the start of miscible in 1995 was shown in figure 3 . Once the arrival of gas front to upper block, then that was an immediate proximity to the gas cap, and the saturation of oil retains its normal value of 0.80 (see in Figure 2A) and which will remain/stands there for total 65 years (until 2070). Corresponding saturation of oil slowly falls to the value of 0.10 and it continues to fall gradually while producing very slow recovery of oil (see in Figure 2C). Even though with 65 years of $\mathrm{S}_{\mathrm{g}}$ constant profile, the viscosity of oil continues to increase. It indicates that medium components and heavy components were extracted from block in oil reservoir, which leads to increase in viscosity and reduction in oilvolume. The block $(25,14,6)$ which witness a complete recovery of oil is indicated by zero values of oil viscosity in year 2087 (see in Figure 2B). The maximum saturation values of oil shown in Figure $2 \mathrm{~A}$ and respective zero saturation oil shown in figure $2 \mathrm{C}$ and this is done by the gravity drained oil's trailing edge. 


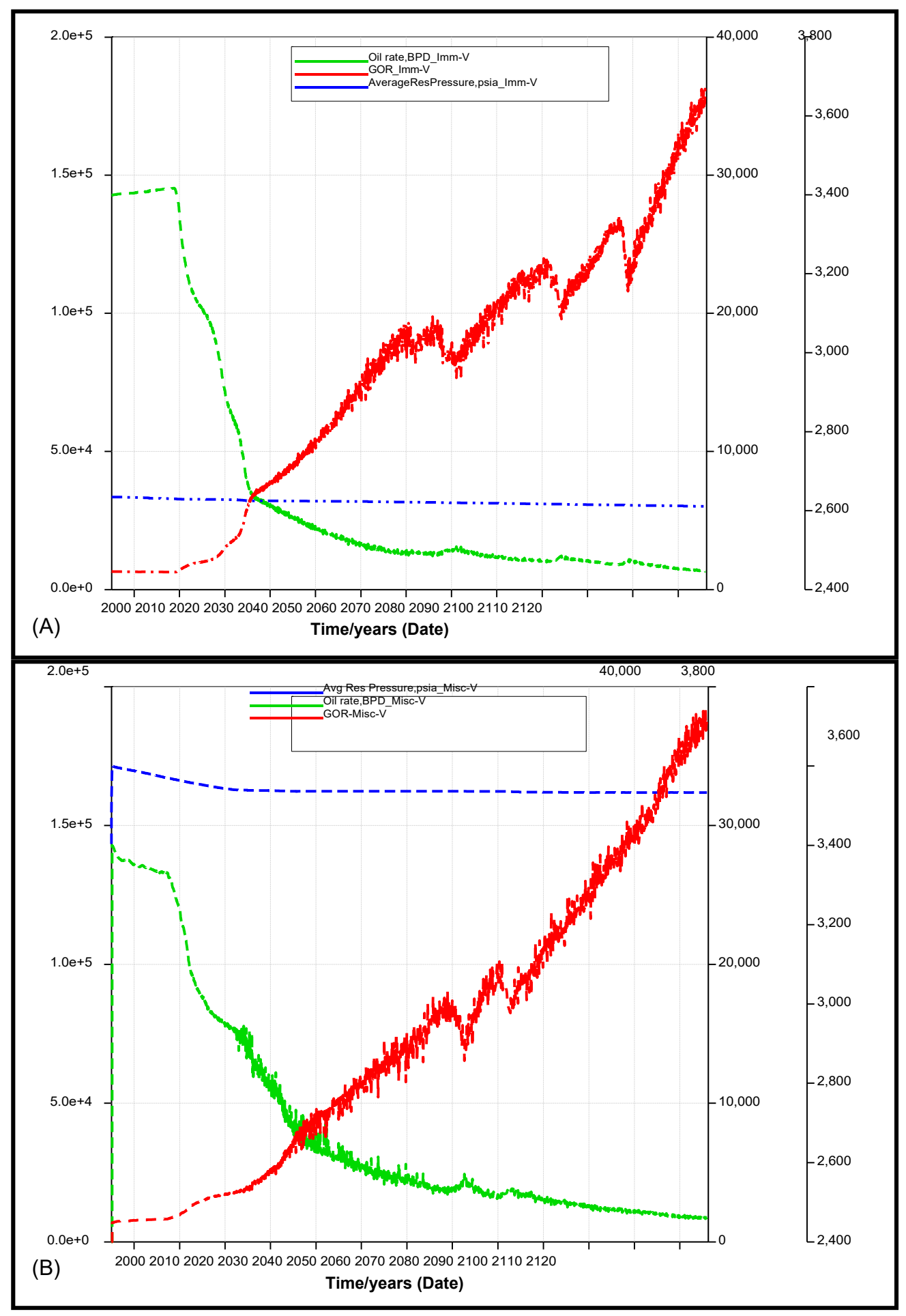


In the year of 2013, it was observed that sudden fall of oil saturation and sharp increase in gas saturation in the block $(25,14,7)$. It is pointed by the gas flood front arrival. During this time oil reservoir can experience both minor extraction and oil swelling represented by corresponding rise and fall of oil viscosity in figure $2 \mathrm{~B}$. But after the arrival of gas flood front, viscosity of oil experiences only its rise, indicating that the the mechanism which is used to recover the reservoir oil which was left behind the flood front of $\mathrm{CO}_{2}$ takes important role. At this time the values of oil saturation remains stable at values about 0.04 (figure $2 \mathrm{C}$ ). Once oil in reservoir is gravity drained downward from upper blocks $(25,14,6)$, saturation of oil starts to fall gradually earlier than its complete recovery in the year of 2120 (nearly over 32 years after gas flood front arrival). Abrupt vertical drop in the values of viscosity indicated by trailing edge in leaving $(25,14,7)$ block of oil which is gravity drained.

Same oil viscosity, oil saturation and gas saturation profiles are shown in block $(25,14$, 8 ). The arrival of flood front in gas is indicated by the reduction in oil saturation and rise in gas saturation. The viscosity of oil will experienced its decline which is coming from swelling earlier than arrival of $\mathrm{CO}_{2}$ flood front but rise in its consistent later. These results again indicate that the oil in reservoir behind leading edge of gas flood front was recovered by the mechanism used to extract, along with gravity drainage mechanism.

For further confirmations, the observations are recorded by the sectional-views of oil saturation, gas saturation and oil viscosity properties in these following blocks and are represented symbol of 'star' in Figure 4A via figure 4L for variations occurred in following properties from begin (1996) to the last part (2126) of the Case-VII in secondary flooding in miscible of $\mathrm{CO}_{2}$. The layers of oil zone is indicated by the red numbers on the top left of right in figure, and top down in production is target zone and it also indicates the horizontal and vertical production (layer-8) wells. The starting properties of this block $(25,14,6)$ at initial stage of miscible flood that is in the year of 1995 are shown by symbol star in figure 4A, 4B, and $4 \mathrm{C}$. The majority of oil recovery (figure $4 \mathrm{~F}$ ) effected the gas saturation that is increased by a value which is higher than 0.80 was shown in Figure $4 \mathrm{D}$ and this is by using B-L type displacement. Though the oil components are extracted from this block (figure 4E) is indicated by corresponding rise in viscosity of oil in layer- 6 .

After reaching the block $(25,14,8)$ the gas flood front in the year of 2024 that was shown in figure $4 \mathrm{G}$ and then it is followed by the front of miscible. Due to the continued gas production, the viscosity of oil in the year looks like rise in some blocks and in some upper blocks in layers 7 and 6 seems reduced, nearly zero values (figure 4H). The zero values indicates that the oil was completely recovered that was behind the flood front of gas by extracting the components of oil. It has to be remember the oil was not completely recovered from these layers. figure $4 \mathrm{~J}$ shows that the increase in gas saturation not attain the values in 2126 that are observed in the year 2024, it was when first breakthrough of gas occurred. As shown in figure $6-8 \mathrm{~K}$, The values of viscosity of oil drops to zero in almost of the layers 6 and 7. It's values reached higher in 2126 than (in layer-8) those observed before in 2003, 24. This explains the further extraction process at the time of downward movement in the zone miscible along continuing to drain the oil present under gravity which was from upper layer. figure 6-8L shows the respective saturation of oil at final stage of miscible flood of $\mathrm{CO}_{2}$. 


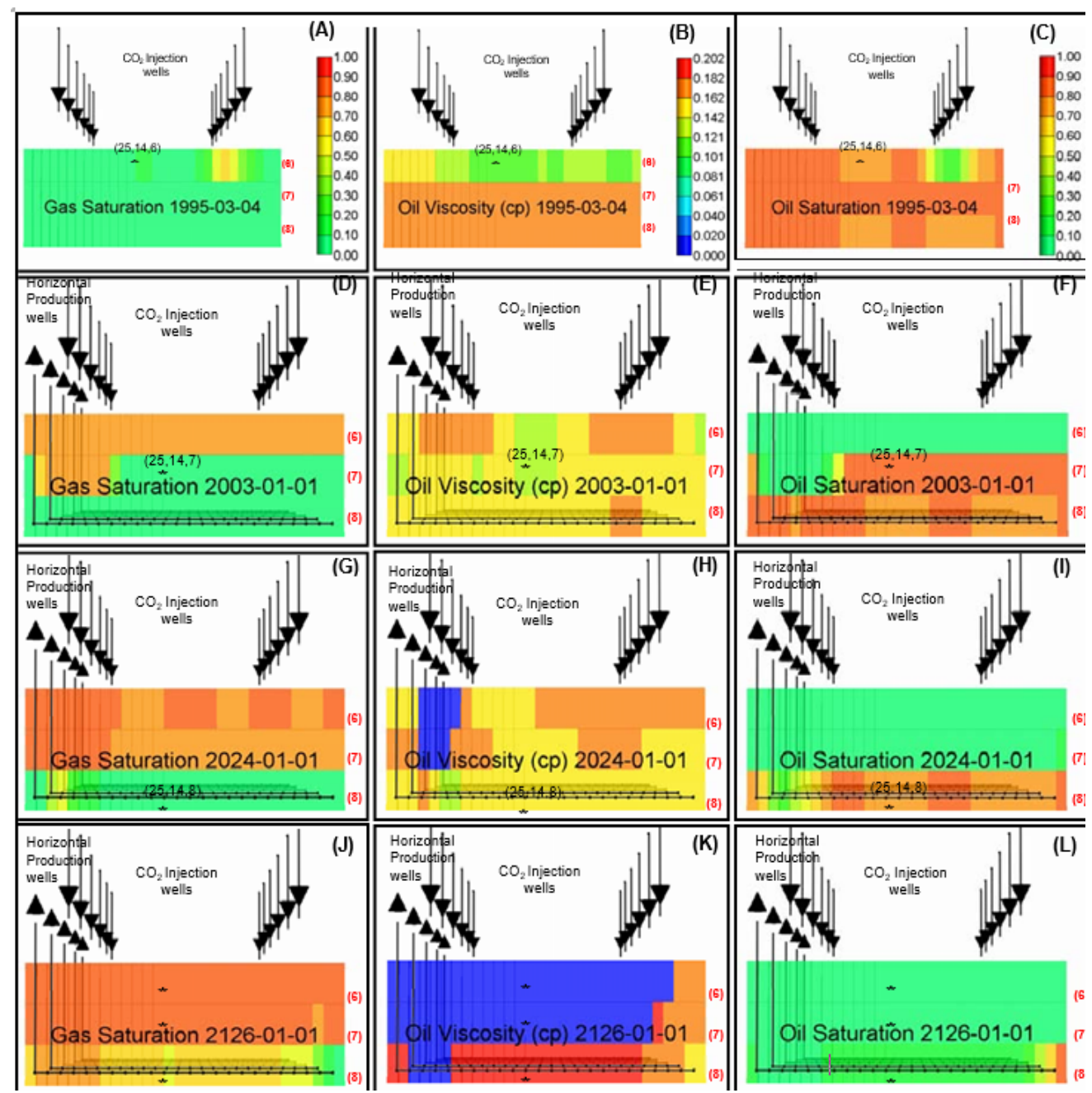

Fig. 3. Mechanisms for Oil recovery except the mechanism of gravity drainage in blocks $(25,14,6),(25,14,7)$ and $(25,14,8)$ in top-down EOR process of gravity drainage assisted by $\mathrm{CO}_{2}$. Process Selection Map: Miscible vs. immiscible EOR process of gravity drainage assisted by $\mathrm{CO}_{2}$.

To obtain optimized oil recovery from miscible or immiscible $\mathrm{CO}_{2}$ injection, the ultimate incremental oil recoveries of selected well rate constraints of Case I - VII vs incremental pore volumes of $\mathrm{CO}_{2}$ injected is shown in figure 4. 


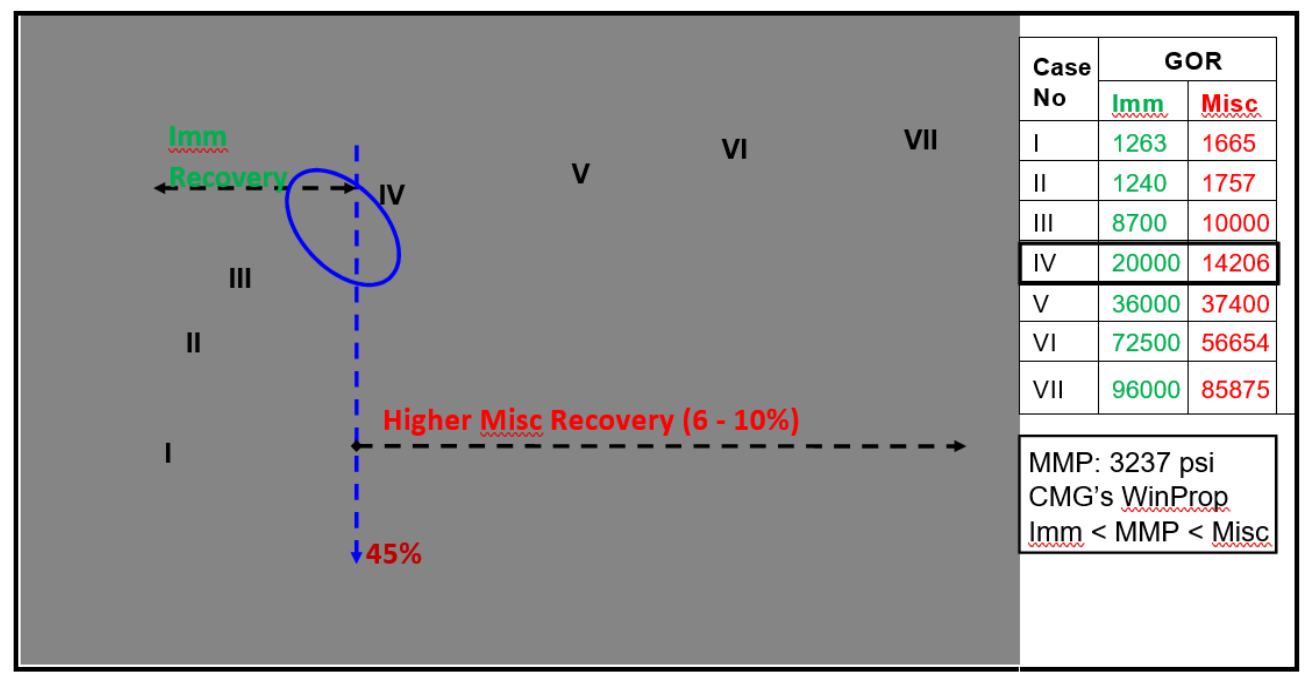

Fig. 4. General selection map for immiscible Vs. miscible process - Case-I via Case-VII

From the plot of ultimate recovery vs pore volume, $\mathrm{CO}_{2}$ injected $\left(\mathrm{PV}_{\mathrm{CO} 2}\right)$ for Cases I, II \& III, the immiscible recovery is high over miscible. For Case IV of the pore volume of 0.45 $\mathrm{CO}_{2}$ injected $\left(\mathrm{PV}_{\mathrm{CO} 2}\right)$ achieved identical oil recovery with immiscible at $58.25 \%$ and miscible at $58.88 \%$ of $\mathrm{CO}_{2}$-assisted gravity drainage EOR processes. This scenario reversed for Cases V, VI \& VII well constraints. They have shown $70.44,75.93$ and $78.86 \%$ for Case-V, Case-VI and Case-VII respectively with ultimate recoveries of $64.20 \%, 67.48 \%$ and $64.20 \%$.

\section{GRID REFINEMENT: For reservoir with $50^{\circ} \mathrm{API}$ Oil}

As there are no investigations on the recovery of gravity drainage oil assisted by $\mathrm{CO}_{2}$ a base model $(50 \times 30 \times 10: 600 \times 400 \times 150)$ considered for the above studies to conclude the miscible and immiscible $\mathrm{CO}_{2}$ injection above 132 years can yield optimum recovery of oil of $78.85 \%$ and $69.15 \%$ respectively in process of EOR gravity drainage assisted by $\mathrm{CO}_{2}$. The effects of the grid - size and grid - thickness for miscible $\mathrm{CO}_{2}$ injection are tabulated below considering the base model of the grid $(50 \times 30 \times 10)$ for Case - VII \& Case - IV with each grid size of (600ft x $400 \mathrm{ft} \times 150 \mathrm{ft})$.

\section{EFFECT OF GRID SIZE}

To understand the effect of grid size on the incremental recovery of oil the base model is reduced to two dimensions ( $\mathrm{x}$ and $\mathrm{y})$. So that initially the base model $(600 \mathrm{ft} \mathrm{x} 400 \mathrm{ft})$ is reduced to half $(300 \mathrm{ft} \times 200 \mathrm{ft})$ and one fifth $(120 \mathrm{ft} \times 80 \mathrm{ft})$. The incremental recovery of half base model (300ft $x$ 200ft) for Case - VII is $79 \%$ which is identical to the two dimensions base model (600ft x 400ft). The same incremental recovery for Case IV was achieved at $45 \%$ of $\mathrm{CO}_{2}$ injected PV (Pore Volume). 
Table 2. Details of grid thickness (layers) and grid size studies for both the Case-VII and Case-IV

\begin{tabular}{|c|c|c|c|c|c|}
\hline & Case & $\begin{array}{l}\text { Number of gri } \\
\text { blocks (i, j, k) }\end{array}$ & $\begin{array}{l}\text { Grid dimensions }(x, y \\
\text { and } z \text { ) }\end{array}$ & Comments & $\begin{array}{l}\text { Comparison } \\
\text { parameters }\end{array}$ \\
\hline \multirow[t]{5}{*}{ Grid size } & \multirow{3}{*}{ I } & $50 \times 30 \times 10$ & $600 \mathrm{ft} \times 400 \mathrm{ft} \times 150 \mathrm{ft}$ & Base Model & \multirow{7}{*}{$\begin{array}{l}\text { Incremental } \\
\text { EOR, GOR and } \\
\text { water cut vs. } \\
\text { PVCO2inj; and } \\
\text { years of } \\
\text { production }\end{array}$} \\
\hline & & & & & \\
\hline & & $50 \times 30 \times 10$ & $300 \mathrm{ft} \times 200 \mathrm{ft} \times 150 \mathrm{ft}$ & $\begin{array}{l}\text { x \& y dimensions } \\
\text { Reduced }\end{array}$ & \\
\hline & 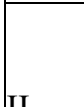 & $50 \times 30 \times 30$ & $600 \mathrm{ft} \times 400 \mathrm{ft} \times 50 \mathrm{ft}$ & Base Model & \\
\hline & & $50 \times 30 \times 30$ & $120 \mathrm{ft} \times 80 \mathrm{ft} \times 50 \mathrm{ft}$ & $\begin{array}{l}\mathrm{x} \text { and } \mathrm{y} \text { dimensions } \\
\text { reduced }\end{array}$ & \\
\hline \multirow{2}{*}{$\begin{array}{l}\text { Grid } \\
\text { Thickness }\end{array}$} & \multirow{2}{*}{ I } & $50 \times 30 \times 10$ & $600 \mathrm{ft} \times 400 \mathrm{ft} \times 150 \mathrm{ft}$ & Base Model & \\
\hline & & $50 \times 30 \times 30$ & $600 \mathrm{ft} \times 400 \mathrm{ft} \times 50 \mathrm{ft}$ & $\begin{array}{l}\text { Layer thickness } \\
\text { Reduced }\end{array}$ & \\
\hline
\end{tabular}

\section{Conclusion}

It is an attempt in order to optimize recovery of oil by using EOR process in gravity drainage assisted by $\mathrm{CO} 2$. The aim of these all investigations is (1) To identify best mechanism and to develop one general method selection map in order to choose in between the miscible and immiscible recovery process; (2) For study grid size effects using gridrefinement. Lastly, operational mechanisms which are used to recovery of oil in gravity drainage of all gravity methods which are assisted by $\mathrm{CO}_{2}$ are identified.

In every study on reservoir simulation, to satisfy/agree the injection rates of $\mathrm{CO}_{2}$ are kept smaller than the stable and critical rates of gas injection.

The selection of miscible and immiscible EOR process of gravity drainage assisted by $\mathrm{CO}_{2}$ is guided by the map which is generated by the use of numerical simulations in base model $(50 \times 30 \times 10: 600 \mathrm{ft} \times 400 \mathrm{ft} \times 150 \mathrm{ft})$ (figure 4). Furthermore, it was suggested that base model produces the optimum recovery of oil is $78.85 \%$ and $69.15 \%$ in miscible and immiscible process respectively about 132 years of injected $\mathrm{CO}_{2}$.

The dimensions of $x$ and $y$ are reduced nearly half $(300 \mathrm{ft} \times 200 \mathrm{ft})$ of the original base model dimensions $(600 \mathrm{ft} \times 400 \mathrm{ft})$ in case of both IV, VII in well rated constraints combination while studying the grid size effect in the incremental recovery. Figure 1 concludes that at 180 pore volumes of injected $\mathrm{CO}_{2}$ produces similar incremental recovery of oil of $79 \%$ by the reduced grid size $(300 \mathrm{ft} \times 200 \mathrm{ft} \times 150 \mathrm{ft})$ and original base model $(600 \mathrm{ft}$ $\times 400 \mathrm{ft} \times 150 \mathrm{ft})$. At injected $45 \% \mathrm{PV}_{\mathrm{CO} 2}$ in case-IV of same profile of oil recovery $(60 \%)$ was attained. From these results it is clear that in good rated constraint combination indicates the effect of grid size has negligible in incremental recovery at reservoir scale using EOR 
process of gravity drainage assisted by $\mathrm{CO}_{2}$. Identical outcomes are presented by Gillham and Fassihi (1993) in the studies of air injection but they varied just the length of $\mathrm{x}$-dimension.

The thickness of grid is minimized to $50 \mathrm{ft}$ when compared with the base model has thickness of $150 \mathrm{ft}$. The performance of the gravity drainage incremental recovery of oil assisted by $\mathrm{CO}_{2}$ which points out reduced model produces 6-16\% (Case-VII), (case-IV) of incremental recovery of oil when compared to base model. By these results it is clear that with smaller grid models yields a better incremental profile of EOR even at lower volumes of pore with injected $\mathrm{CO}_{2}$. It provides the effective oil drainage which has gravity-drained from upper to beneath layers. Furthermore, the oil present in these blocks is not allowed. This really matters in layer in which horizontal production well was completed. According to the outcomes of Gillham and Fassihi (1993) and Ypma (1985) concluded that for the optimizing the recovery of oil the layers in the bottom most must be thinner. The investigations in present study suggested that the thin layers can facilitate the optimum recovery of oil in gravity drainage also in upper layers.

The optimized grid recovered $98.4 \%(50 \times 30 \times 30: 120 \mathrm{ft} \times 80 \mathrm{ft} \times 50 \mathrm{ft})$ at $9 \mathrm{PV}_{\mathrm{CO} 2 \mathrm{inj}}$ (over 132 years) and also $94 \%$ at $3 \mathrm{PV}_{\text {CO2inj }}$ (over 40 years) recoveries which are incremented in the process of miscible at one-fifth low rate of oil production. Due to this higher recovery leads to utilization of optimized grid for all remaining simulations. Diffusion effects that are present in homogeneous reservoir $\left(\mathrm{k}_{\mathrm{v}} / \mathrm{k}_{\mathrm{h}}=1.0\right)$ are neglected in these studies.

\section{References}

[1] Ali Farouq, S.M. and Thomas, S. 1996. The promise and problems of enhanced oil recovery methods. Journal of Canadian Petroleum Technology,,35(7).

[2] Alston, R.B., Kokolis, G.P. and James, C.F. 1985. $\mathrm{CO}_{2}$ Minimum Miscibility Pressure: A Correlation for Impure CO2 Streams and Live Oil Systems. SPE 11959, SPE Journal: 268-274..

[3] Backmeyer, L.A., Guise, D.R., MacDonell, P.E. and Nute, A.J. 1984. The Tertiary Extension of the Wizard Lake D-3A Pool Miscible Flood. SPE 13721; presented at the SPE 59th Annual Technical Conference and Exhibition held in Houston, Texas.

[4] Bon, J. and Sarma, H.K. 2004. A Technical Evaluation of a $\mathrm{CO} 2$ flood for EOR Benefits in the Cooper Basin, South Australia. SPE 88451 - SPE Asia Pacific Oil and Gas Conference and Exhibition Perth, Australia, October, 18-20.

[5] Cardenas, R.L., Alston, R.B., Nute, A.J. and Kokolis, G.P. 1981. Laboratory Design of a Gravity Stable, Miscible $\mathrm{CO}_{2}$ Process. SPE 10270: presented at 56th Annual Fall Technical Conference and Exhibition of the SPE of AIME, held in San Antonio, TX.

[6] Cardwell, W.T. and Parsons, R.L. 1949b. Gravity Drainage Theory. Trans. AIME, 179: 199-215.

[7] Dake, L.P. 2001. The Practice of Reservoir Engineering (Revised Edition). Developments in Petroleum Science. Elsevier Science B.V., Amsterdam.

[8] Emera, M.K. and Sarma, H.K. 2005a. Genetic Algorithm (GA)-based Correlations Offer More Reliable Prediction of Minimum Miscibility Pressures (MMP) between the Reservoir Oil and CO2 or Flue Gas. CIPC 2005-003, presented at the Canadian International Petroleum Conference (CIPC), $56^{\text {th }}$

[9] Farouq Ali, S.M. and Thomas, S. 1996. The promise and problems of enhanced oil recovery methods. Journal of Canadian Petroleum Technology,35(7).

[10] Glasø, Ø. 1985. Generalized Minimum Miscibility Pressure Correlation. SPE 12893-PA, SPE Journal, 25(6): 927-934. 
[11] Hagen, J. and Kvalheim, B. 1990. Oseberg Field. In: M. Halbouty (Editor), Giant Oil and Gas Fields of the Decade: 1978-1988. The American Association of Petroleum Geologists, Stavanger, Norway, pp. 417-428.

[12] Ho, C.K. and Webb, S.W. 2006. Gas Transport in Porous Media. Theory and Applications of Transport in Porous Media, 20. Springer.

[13] Holtz, M.H., Nance, P.K. and Finlay, R.J. 1999. Reduction of Greenhouse Gas Emissions through underground $\mathrm{CO}_{2}$ sequestration in Texas Oil and Gas Reservoirs, The University of Texas, Austin.

[14] Howes, B.J. 1988. Enhanced Oil Recovery in Canada: Success in Progress. Journal of Canadian Petroleum Technology, 27(6): 80-88.

[15] Lewis, J.O. 1944. Gravity Drainage in Oil fields. AIME Petroleum Transactions, 155(133). Li, H., Schechter, D.S. and Grig, R.B. 2000. Experimental Investigation of $\mathrm{CO}_{2}$ Gravity Drainage in a Fractured System. SPE 64510 - SPE Asia Pacific Oil and Gas

[16] Mathiassen, O.M. 2003. $\mathrm{CO}_{2}$ as Injection Gas for Enhanced Oil Recovery and Estimation of the Potential on the Norwegian Continental Shelf, Norwegian University of Science and Technology, Trondheim/Stavanger.

[17] Moritis, G. 1995. Impact of production and development RD\&D ranked. Oil and Gas Journal, 93(44).

[18] Rao, D.N. 2006b. Gas Assisted (CO2) Gravity Drainage IOR; The Process and a Louisiana Field Project, invited talk at the Independents Day@ IOR 2006, Tulsa, OK.

[19] Ruark, A.E. 1935. Inspectional Analysis: A Method Which Supplements Dimensional Analysis. Journal of Elisha Mitchell Scientific Society, 51.

[20] Sajadian, V.A. and Tehrani, D.H. 1998. Displacement Visualization of Gravity Drainage by Micromodel. SPE 49557, presented at the 8th Abu DhabiInternational

[21] Sharp, J.M. 1975. The potential of Enhanced Oil Recovery Processes. Society of Petroleum Engineers of AIME: SPE 5557.

[22] Shook, M., Li, D. and Lake, L.W. 1992. Scaling Immiscible Flow through Permeable Media by Inspectional Analysis. In-Situ 4:311-349.

[23] Terwillinger, P.L., Wilsey, L.E., Hall, H.N., Bridges, P.M. and Morse, R.A. 1951. An Experimental and Theoretical Investigation of Gravity Drainage Performance. Petroleum Transactions, AIME, 192: 285 - 295.

[24] Vilela, M.J., Gharsalla, M., ElGhmari, M. and Majdoub, A. 2007. Performance Evaluation of a Reservoir under EOR Recovery: Intisar 'D' reef, Concession 103, Lybia. SPE 104619, presented at the 15th SPE Middle East Oil and Gas Show and Conference, Bahrain, March 11-14.

[25] Whitson, C.H. 1983. Characterizing Hydrocarbon Plus Fractions. Society of Petroleum Engineers Journal: pp. 683-694.

[26] Wylie, P.L. and Mohanty, K.K. 1999a. Effect of Wettability on Oil Recovery by Near Miscible Gas Injection. SPE Reservoir Evaluation and Engineering: SPE 59476, 2(6).

[27] Yellig, W.F. and Metcalfe, R.S. 1980. Determination and Prediction of CO2 Minimum Miscibility Pressures. SPE 6548, Journal of Petroleum Technology (SPE6548): 160-16 